\title{
Ancoragem e circulação crítica na reconstituição do espaço público em Terremoto santo
}

\section{Anchorage and critical circulation in the re-elaboration of public space in Terremoto santo}

Eduardo Paschoal de Sousa ${ }^{1}$ 


\section{Resumo}

Este artigo se propõe analisar as interpretações do curta-metragem Terremoto santo (Bárbara Wagner e Benjamin de Burca, 2017) ao longo de suas inúmeras esferas de recepção - como o circuito de festivais, a crítica institucionalizada, as redes sociais e as narrativas da própria produção, confrontada com determinadas formas de olhar para o filme. Refletimos, assim, sobre como a obra realiza uma ancoragem em sua circulação, a partir desse complexo crítico, ao recompor suas leituras possíveis, ampliando seu espaço público de circulação e remontando as narrativas que se formaram e que estão à disposição do espectador no momento de sua deliberação.

Palavras-chave

Crítica audiovisual, narrativa, ancoragem, complexo crítico.

\section{Abstract}

This article analyzes the interpretations of the short film Holy tremor (Terremoto santo, Bárbara Wagner and Benjamin de Burca, 2017) throughout its several spheres of reception - such as film festivals, institutionalized critiques, social networks, and the narrative from the production team itself, confronted many times with certain ways of looking at the film. We thus reflect on how this movie anchors itself to its circulation due to its critical complex, by re-elaborating its possible interpretations, expanding its public diffusion space and reassembling the narratives formed and left available to the viewer at the moment its deliberation.

\section{Keywords}

Audiovisual critique, narrative, anchorage, critical complex. 
Ao analisar uma obra audiovisual, é importante refletir sobre a dinâmica de sua circulação. Muito além de olhar para um filme como algo fechado em si mesmo, é necessário observar a forma como ele é lido, em diferentes contextos e por diferentes grupos de espectadores, com suas próprias experiências culturais, sociais e políticas, que influenciam decisivamente na concepção das obras. Por isso, para reconstituir as interpretações diversas e possíveis de um mesmo objeto audiovisual, é fundamental reconstituir seu espaço público de circulação, a forma pela qual se constroem suas leituras e as interpretações que obra mobiliza no decorrer de sua recepção crítica.

Neste artigo, buscaremos analisar a maneira como o curta-metragem Terremoto santo (Bárbara Wagner e Benjamin de Burca, 2017) produziu diversas interpretações, muitas vezes postas em conflito, ao longo de suas inúmeras esferas de recepção - como o circuito de festivais, a crítica institucionalizada, as redes sociais e as narrativas da própria produção, confrontada com determinadas formas de se olhar para o filme. Analisaremos, portanto, como a obra realiza uma ancoragem em sua circulação e, ao reconstruir as diversas interpretações em conflito que se mobilizam a partir desses contatos, procuraremos recompor as leituras possíveis sobre o filme, ampliando seu espaço público de circulação e remontando as narrativas que estão à disposição do espectador no momento de sua deliberação sobre a obra.

Para isso, buscaremos inicialmente realizar um percurso teórico ao redor do conceito de ancoragem, desde Roland Barthes (1964) até Guillaume Soulez (2013a), incluindo, além disso, a maneira como o compreendemos; em seguida, tentaremos remontar as diversas interpretações do filme quando de suas exibições, críticas e circulação; e por fim buscaremos agrupá-las em possíveis grupos temáticos de interpretação, mobilizados pela produção da obra, pela crítica institucionalizada e pelas redes sociais, para compôr o que podemos classificar como espaço público, a partir das múltiplas leituras construídas sobre a obra, fruto, muitas vezes, de ruídos gerados pelo próprio filme. 


\section{A ancoragem da obra em seu complexo crítico}

Em um trabalho considerado clássico para a interpretação do texto e da imagem, utilizando como objeto anúncios publicitários, Roland Barthes (1964) aponta para uma cadeia flutuante de significados na imagem, derivada de sua polissemia, ou seja, das inúmeras possibilidades de apreensão de sentido a partir da figura pictórica. O semiólogo analisava, em A retórica da imagem, a necessidade do texto, ou da mensagem escrita que acompanhava os anúncios publicitários, de apoiar a mensagem imagética e escolher, dentre as inúmeras interpretações possíveis, uma que fosse mais coerente com o que se queria passar. A essa operação, que atua para explicar ou intensificar o efeito da imagem, o autor (1964, p. 44) dá o nome de ancoragem².

O autor difere, no entanto, as palavras utilizadas para fixar um significado de uma outra categoria possível, empregada como complementaridade do sentido narrativo, ou seja, que realmente é necessária para desencadear uma ação: é o caso, por exemplo, da diferença entre a legenda nos anúncios publicitários (função de âncora) e os diálogos no cinema (função de relais, conforme o autor):

A ancoragem é a função mais frequente da mensagem linguística; nós a encontramos comumente na fotografia jornalística e na publicidade. A função de relais é mais rara (ao menos no que diz respeito à imagem fixa); nós a encontramos sobretudo em charges e nos quadrinhos. Aqui a palavra (mais geralmente um pedaço de diálogo) e a imagem estão em uma relação de complementaridade. [...] Essa palavra-relais se torna muito importante no cinema, onde o diálogo não tem uma função de simples elucidação, mas onde ele faz avançar verdadeiramente a ação, colocando na sequência de mensagens um sentido que não se encontra na imagem. (BARTHES, 1964, p. 45, tradução nossa) ${ }^{2}$

A partir de Barthes (1964), em uma ampla cadeia de significados mobilizada pela imagem pictórica, o texto atuaria, em uma de suas funções, como uma

2 No original: "L'ancrage est la fonction la plus fréquente du message linguistique; on la retrouve communément dans la photographie de presse et la publicité. La fonction de relais est plus rare (du moins en ce qui concerne l'image fixe); on la trouve surtout dans les dessins humoristiques et les bandes dessinées. Ici la parole (le plus souvent un morceau de dialogue) et l'image sont dans un rapport complémentaire. [...] Rare dans l'image fixe, cette parole-relais devient très importante au cinéma, où le dialogue n'a pas une fonction simple d'élucidation mais où elle fait véritablement avancer l'action en disposant dans la suite des messages, des sens qui ne se trouvent pas dans l'image". 
âncora de sentido, advertindo o leitor sobre a interpretação mais adequada frente a inúmeras possíveis. O teórico Christian Metz (1975), pioneiro na aplicação da semiologia ao cinema, retoma o conceito de Barthes anos depois e o aplica ao cinema, não mais na perspectiva do texto publicitário, mas refletindo sobre como há processos diversos de ancoragem no material fílmico.

O autor (op. cit., p. 38) reflete, inicialmente, sobre o papel do espectador no filme: ao mesmo tempo que tem a certeza de estar presente na diegese fílmica, ele consegue escapar dela - e mantém a consciência de estar em uma sala escura assistindo a uma obra audiovisual. Há, então, alguns elementos na estrutura narrativa e na relação entre imagem e movimento, muito cara à narrativa cinematográfica, que atrai a atenção do espectador e o joga de volta para a tela. É essa dinâmica, a partir de elementos que atuam como imãs e que levam o espectador novamente para dentro do filme sempre que ele deseja sair, que Metz classifica como ancoragem. Ela atua para que o código cinematográfico não tenha que impor explicitamente ao espectador a atenção exclusiva ao filme, mas o faça de maneira implícita, a partir de recursos do próprio filme. Ou seja, para o autor, a ancoragem fílmica é o que mais nos atrairia à obra, ao mundo da narrativa.

Dois anos depois, Metz (1977) retorna a esse conceito para aplicá-lo em outra esfera do cinema: não são mais certos elementos da narrativa fílmica que produzem ancoragem, mas o próprio filme, como uma maneira de conectar a história ao mundo. Para ele, a realidade da imagem cinematográfica atua como uma âncora em relação à realidade do mundo. Dessa forma, é essa dinâmica entre imagem do cinema e reflexo do mundo que seria, para ele, uma ação de ancoragem. O autor deixa claro, no entanto, que o filme não ressignificaria o mundo histórico, mas atuaria como ponte entre a realidade da imagem e a do cotidiano.

Ao realizar essa reapropriação teórica do termo, Metz (op. cit.) retoma Barthes e descreve que, da mesma maneira que o texto na imagem publicitária ancora uma mensagem única dentre uma grande cadeia de significantes, o filme também ancoraria uma determinada realidade do mundo histórico frente a uma quantidade 
imensa de interpretações possíveis. Ele seria, nessa perspectiva, um documento - não um retrato exato, mas um indício possível de determinado tempo histórico.

Em uma ampla pesquisa sobre a interpretação das imagens, Martine Joly (1994) volta às considerações sobre o papel do texto escrito na ancoragem das imagens e considera essa função, a partir de Barthes e Metz, muito presente no cinema, mas ainda no sentido proposto pelos estudos anteriores. Ela avança na concepção de ancoragem das imagens publicitárias e nas instruções presentes na legendas jornalísticas, legando ao cinema o papel de ponte entre as narrativas e o mundo histórico, conforme Metz já havia proposto.

Ao produzir o Dicionário crítico e teórico do cinema, Jacques Aumont e Michel Marie (2003) vão incluir o termo "ancoragem" entre suas definições. Eles o classificam a partir de Barthes, Metz e Joly, mas atribuem a ele um sentido de caráter de controle na apreensão do significado. Segundo os autores (op. cit., p. 17), é como se a narrativa fílmica, a oralidade da narração ou até mesmo a mensagem escrita - no caso das cartelas e dos letreiros do cinema silencioso atuassem como uma ancoragem para o filme, em uma tentativa de explicitar o que se mostra. Esses suportes, orais ou textuais, não ancorariam uma interpretação desejável a partir de muitas possíveis, mas seriam redundâncias necessárias na tentativa de direcionar uma única maneira de conduzir o espectador à narrativa. Portanto, mais uma estratégia de controle de significados que de apenas a sugestão de interpretações.

São as maneiras de escolher algumas dentre as várias interpretações fílmicas possíveis que Roger Odin $(1997,2001)$ classifica os movimentos de ancoragem da obra fílmica. Para o autor, há modos específicos de leitura que direcionam a maneira como o espectador compreenderá o filme. Esses modos dependem do gênero fílmico (ficção, documentário, filme de família), mas também de dimensões culturais e sociais, como o contexto político e o tempo histórico em que o filme é visto. A mudança contextual, portanto, não vai apenas interferir no tipo de leitura, mas também na interpretação do espectador em relação à obra. 
É possível elaborar, na perspectiva de Odin (2011), a leitura de trechos de uma obra ficcional como documentário, ou mesmo ficcionalizar filmes que propõem estabelecer uma relação direta com o mundo histórico. Esses modos de leitura podem atuar como ancoragens da obra em determinado contexto histórico, que não é fixo nem estanque, mas alterado à medida que essas negociações entre obra e variáveis múltiplas de leitura se modificam. Portanto, ao invés de limitar e determinar o direcionamento necessário à interpretação da obra, a ancoragem contextual, que depende (entre outros) de fatores políticos, sociais, culturais e de gênero fílmico, ampliam as interpretações possíveis do objeto audiovisual, levando a uma pluralidade de significados e leituras de uma mesma obra.

Para além dos inúmeros modos de leitura propostos por Odin em suas produções, o teórico Guillaume Soulez (2011), a partir da semiopragmática, destaca duas operações principais de leitura que o espectador depreende inicialmente a partir da obra audiovisual. A primeira seria uma leitura poética, que faz com que ele mergulhe nela e a compreenda como um mundo em si. Segundo o autor, ao se colocar na narrativa fílmica, o espectador compreende diegeticamente a realidade, considerando as relações lógicas presentes no tecido narrativo, ainda que elas não façam correlação ou mesmo sentido com o mundo histórico. Questões próximas ao estilo e à estética fílmica estariam nessa primeira dimensão de leitura, a que vê a obra como um instrumento fechado e indissociável e não estabelece relação contextual que não seja com os próprios modos narrativos - o gênero, o estilo do diretor, a forma como o filme constrói seus personagens e seus arcos dramáticos.

A segunda esfera possível seria a da leitura retórica, que trata as imagens e os sons de um produto audiovisual como tomadas de posição, de argumentos e, algumas vezes, de provas sobre o mundo histórico. Esse tipo de leitura estaria diretamente conectado com o contexto de circulação político, social e cultural das obras, ou seja, a relação da obra em contexto faz com que sejam expostos os meandros que levaram a sua concepção. Ou ainda: a leitura retórica comporia uma concepção da obra que poderia variar de acordo com o diálogo social que ela provoca. Dessa forma, as leituras dependem de sua circulação contextual e não são, portanto, objetivas 
e diretas, mas sempre passíveis de serem remontadas de acordo com o espaço público de circulação. Essa maneira de compreender o filme também atribui ao espectador um caráter ativo frente à obra, como componente fundamental de sua interpretação, e não um elemento passivo da recepção fílmica, o que não constituiria um diálogo obra-espectador.

A partir da ideia da leitura retórica da obra, Soulez (2013a) formula também a deliberação das imagens, mecanismo que ocorre junto ao espectador. Esse seria um momento em que, a partir de diversas interpretações possíveis em relação a um determinado filme, o receptor poderia se colocar em acordo ou desacordo, chegando também a construir suas próprias formulações a partir do objeto audiovisual. 0 espectador seria, então, um operador dessa pluralidade e conflituosidade, e não apenas um representante de uma leitura em potencial, dentre outras possíveis, ou ainda um simples ponto de passagem de determinadas concepções socioculturais.

Para Soulez (2013a, p. 25), a partir da perspectiva de múltiplas interpretações compondo a leitura da obra, a discussão pública não é uma espécie de segundo momento da recepção e não seria fruto da opinião do espectador sobre o filme a que assistiu, por exemplo, mas sim um atravessamento do espectador no momento da interpretação da obra. Por isso a necessidade de analisar, afora a capacidade do espectador de reconhecer um ou outro gênero fílmico, a "maneira pela qual as bifurcações de interpretação se produzem, e de outra parte, as conexões entre essas bifurcações e a ancoragem social das hipóteses de leitura"3 (SOULEZ, 2013a, p. 25, tradução nossa).

É nesse conjunto de interpretações que se constitui o espaço público em torno (mas também sobre) a obra. E é a partir dele que se pode estabelecer um mapeamento das possíveis interpretações que atravessariam o espectador no momento de sua deliberação. Dessa forma, entendemos que o que o autor propõe é que se considere uma ancoragem a partir das interpretações possíveis que se aglutinam em torno (e sobre) uma obra. 
Dessa forma, não é possível pensar nessas análises a partir da individualidade espectatorial, mas sim por meio de interpretações coletivas, que permitam depreender concepções em comum. Para isso, pensamos em analisar remontar o espaço público de circulação da obra a partir de três esferas de produção de sentido e de interpretações: a própria produção, como um conjunto de instruções que partem da enunciação fílmica, mas que a transcendem; a circulação crítica dos filmes, não apenas com a institucionalizada, mas também com a maneira crítica de circulação nas mídias; e, por fim, a partir das discussões que se colocam em rede, cujas interpretações parecem colidir de maneira mais incisiva, geradora de ruídos. É por essas três esferas de interpretação que, por ora, consideraremos o complexo crítico da obra e tentaremos recompor seu espaço público.

\section{O complexo crítico formado a partir das obras e a reivindicação de interpretações}

Ao refletir sobre a esfera crítica de análise de uma obra, é recorrente pensarmos sobre a crítica institucionalizada, ou sobre os críticos especializados. Essa dimensão da avaliação é, muitas vezes, composta por uma forma de leitura que prioriza uma determinada interpretação, que direciona a recepção do filme a uma única chave. Ainda que continue havendo essa priorização da crítica como espaço privilegiado de interpretação da obra, o teórico literário Wolfgang Iser (1996) destaca a capacidade de todo leitor, com fins institucionais ou não, de fazer sua crítica de um produto cultural - no caso dele, especificamente, a literatura.

Para o autor, "antes de tudo o crítico é um leitor como qualquer outro que busca apreender, por meio da consistência estabelecida, a obra como um todo articulado. Nesse processo críticos e leitores têm a mesma competência" (ISER, 1996, p. 46). Mais do que privilegiar a crítica institucionalizada como o espaço único de interpretação possível de uma obra audiovisual, a consideraremos aqui geradora de interpretações possíveis, muitas vezes em conflito, compondo mais um elemento do complexo crítico da obra.

Além disso, ao analisar um produto audiovisual, não podemos deixar de refletir sobre sua esfera de mediação e sua circulação cultural como objeto de mídia. As 
pesquisadoras Rosana Soares e Gislene Silva (2016) apontam para a necessidade de afirmar a potência crítica não apenas no próprio objeto, já que não é interna a ela, "mas também fora dele (no contexto e na recepção). Ou seja, não haveria um modo único de apresentação da realidade ou algo que precisa ser desvelado, mas a reconfiguração do sensível sob outros modos de percepção e significação" (ibid., p. 15). A partir dessa concepção dos objetos de mídia como um produto cultural, é fundamental situá-los, segundo as autoras (ibid., p. 26), "em uma rede de relações geradoras de novos sentidos, observando e articulando suas implicações históricas, políticas, sociais, culturais e econômicas" e, portanto, como sintomas de uma época histórica específica, colocando-os, também eles e suas circulações, em crise.

Aqui, podemos sintetizar uma maneira possível de análise de objetos de mídia: a consideração de que a ancoragem da leitura das obras depende de um contexto político, social, cultural e histórico - portanto, movimentam uma leitura retórica -; a noção de que o espaço público de circulação da obra é amplo e conta com inúmeras interpretações muitas vezes conflituosas; e, por fim, a ideia de que, para remontar essas possíveis interpretações que atravessam o espectador no momento de sua deliberação, há a necessidade de expandir a noção de crítica, a partir da consideração de diferentes esferas de circulação que, de uma forma mais ampla, constituem suas críticas. Podemos considerar, então, que a obra audiovisual ancora não apenas em seu contexto político, social, cultural e histórico, mas sim em um conjunto mais amplo de interpretações, que podemos classificar como complexo crítico.

É na composição desse complexo, que também podemos chamar de espaço público de circulação da obra que se apresentam inúmeras interpretações possíveis, muitas delas conflituosas e que reivindicam alterações na estrutura narrativa ou no próprio tecido fílmico. Há as que mobilizam interpretações a partir de grupos de espectadores, que o sociólogo Jean-Pierre Esquenazi (2011, p. 200) classifica como comunidades de interpretação. Para ele, quando há essa reivindicação, o produto cultural se torna uma obra política, e não há leitura política possível desses produtos que não seja coletiva. É da coletividade que se procura solicitar o entendimento da obra sob determinado viés: "Um produto cultural [...] não se torna uma obra política 
a não ser que se encontre um coletivo decidido e capaz de se fazer endossar essa qualificação aos olhos do espaço público" (ibid., tradução nossa) 4 .

É possível que essa interpretação seja a reivindicação, a partir de determinada comunidade de interpretação, da correção de uma forma de representação equivocada, um conflito identitário, no próprio tecido narrativo. Podemos pensar nesses casos como ruídos a partir dos quais a fruição de interpretações possíveis sobre a obra entram em conflitos mais explícitos, determinando uma dimensão política e social incontornável. Para o autor (ibid., p. 226), quando isso ocorre a obra passa por uma mudança interpretativa que a torna uma exemplificação, ou mais corretamente, uma paráfrase de uma situação política contemporânea.

Há interpelação cultural se um produto cultural industrial provoca em uma comunidade de interpretação um ruído identitário que submerge ou desmantela o contexto normalmente associado ao enunciado-produto, um ruído suscetível de articular a comunidade do produto. Isso suscita, então, uma réplica coletiva capaz de refundar a identidade desse público no terreno sócio-político. ${ }^{5}$ (Ibid., 2011, p. 203, tradução nossa)

Esse ruído pode, muitas vezes, se sobrepor a todas as demais interpretações da obra, levando a própria produção a ter de readequá-la, remontá-la, ou mesmo a se justificar publicamente a respeito de suas decisões e das dimensões interpretativas que a obra tomou, seja pela crítica, seja por determinados grupos de espectadores, que compõem sua circulação social. Tendo em perspectiva essas possibilidades de constituição do complexo crítico e das inúmeras interpretações possíveis - algumas, inclusive, geradoras de ruídos -, iremos, a seguir, analisar a circulação crítica de Terremoto santo, obra que nos permitirá mapear algumas dessas dimensões políticas, sociais e culturais. capable de lui faire endosser cette qualification aux yeux de l'espace public". d'interprétation un trouble identitaire qui submerge ou démantèle le contexte normalement associé à l'énoncéproduit, trouble susceptible d'articuler la communauté au produit. Ce dernier suscite alors une réplique collective capable de refonder l'identité de ce public sur le terrain sociopolitique". 


\section{A estética e o louvor: ruídos nas interpretações de Terremoto santo}

Uma das primeiras sessões de exibição do curta Terremoto santo foi na X Janela Internacional de Cinema do Recife, festival pernambucano conhecido por dar amplo espaço a novos criadores, a filmes com produções independentes e a narrativas diversas, no dia 5 de novembro de 2017. O filme já estava em cartaz como instalação audiovisual na mostra Corpo a Corpo, no Instituto Moreira Salles Paulista, aberta no dia 20 de setembro do mesmo nno $^{6}$, mas foi na sessão em que o curta foi visto na tela de cinema, em que estavam críticos, realizadores, atores envolvidos na produção e o público em geral, que seu impacto foi maior e amplificado nas críticas que se sucederam àquele dia.

Segundo a crítica Bárbara Bergamaschi (2017), em texto no próprio site do festival dias depois, o público do Cinema São Luiz, onde o filme foi exibido, variava entre um fascínio pela obras e a ofensa, e "alternavam entre risos debochados e vaias de desconforto diante da exposição desses cantores (que também estavam presentes na sessão)". Essa reação, segundo ela, tinha a ver com os procedimentos formais de montagem e enquadramento, que davam a sensação de que "seres exóticos estão sendo colocados em uma vitrine como 'objetos de estudo' para um público que assiste a tudo como um 'gabinete de curiosidades'".

O filme, indexado como documentário musical, organiza, a partir de vários clipes de música gospel, uma narrativa fragmentada sobre esse cenário musical. As imagens são plasticamente bem elaboradas, com muitos contraluz e uma preocupação em filmar com gruas e outros equipamentos que permitem panorâmicas, grandes enquadramentos, além de ser favorecido pelo cenário natural que preza por certa exuberância: cachoeiras, matas, morros, riachos. Esses trechos mais idílicos são intercalados por algumas pessoas gravando um programa gospel em uma rádio, cantando suas músicas a capela. O curta se encerra com um grupo de trabalhadores que constroem, com as próprias mãos, uma nova igreja em uma comunidade. 
As imagens (Figura 1 ) se revezam entre a construção e o culto, em uma estética muito próxima à do videoclipe. Talvez por se tratar de um filme pensado também para um espaço de exibição, o curta não parece ter um começo e um fim, podendo ser montado pelo espectador de maneira não linear, no momento em que entra na sala de exibição; ou então pode ser assistido na forma como foi concebido, com uma ordenação narrativa sutil que liga suas diversas sequências.
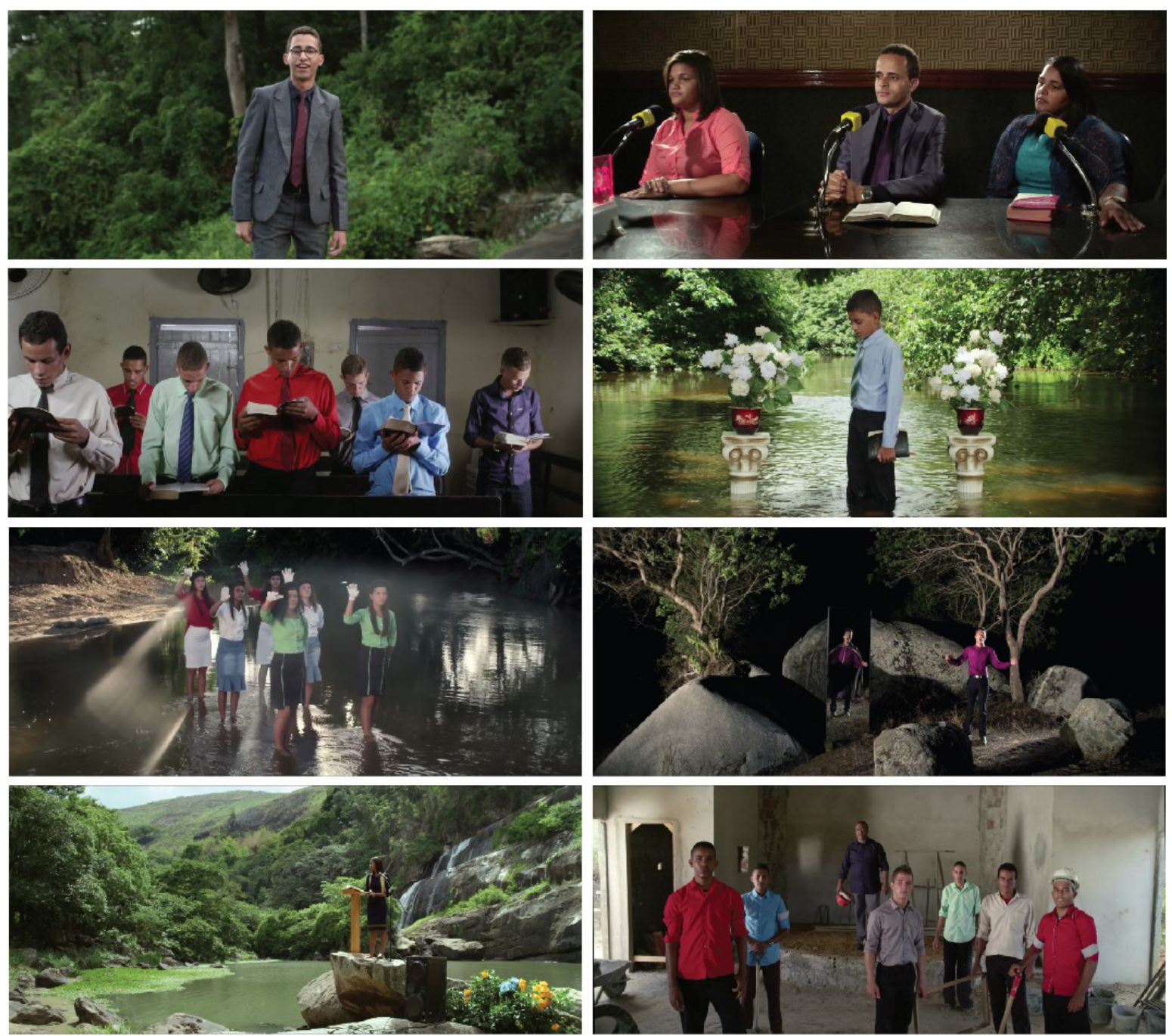

Figura 1: Frames do curta Terremoto santo

Fonte: Terremoto santo, $2017^{7}$. 
A obra foi elaborada em parceria com uma gravadora de música gospel de Palmares, cidade da Zona da Mata pernambucana, muito conhecida por ser o celeiro de artistas musicais de igrejas evangélicas pentecostais e neopentecostais. Segundo a diretora Bárbara Wagner, em entrevista ao curador da exposição Corpo a corpo, Thyago Nogueira (2017, p. 12), o filme foi feito na tentativa de escutar e observar o crescimento da igreja evangélica no país, em "uma região marcada economicamente pela presença dos engenhos de cana-de-açúcar, socialmente pela ligação da casa-grande com a senzala e culturalmente pelo subjugo de rituais e crenças afro e indígena ao domínio da Igreja Católica".

Na mesma entrevista, o diretor Benjamin de Burca (ibid.) detalha o processo de criação, de parceria com os cantores. Segundo Burca, eles propuseram um trabalho coletivo na construção do roteiro e na concepção estética do filme, e as "decisões foram tomadas em conjunto e não levaram em conta apenas as capacidades e talentos, mas também as relações já existentes entre os membros do grupo e suas atuações na igreja e nas comunidades". Sobre a performance dos atores, escolhidas por eles mesmos, o realizador destaca que "o filme toma um espaço híbrido: é documental quando os personagens representam a si mesmos tornando pública sua fé e é ficcional a medida que evidencia a construção teatral das performances" (ibid., p. 13).

A distância entre a intenção dos produtores e a recepção da obra foi significativa. Em uma das críticas, escrita no dia seguinte à primeira exibição da obra em Pernambuco e publicada no site AdoroCinema, o crítico Bruno Carmelo (2017) classifica o curta como uma "composição ultraestetizada e kitsch". E também repercute a recepção do filme na sessão de estreia:

Enquanto parte do público no Cinema São Luiz gargalhava com as cenas, outra parte se mostrava incomodada. Os diretores estariam ridicularizando os artistas, que teriam participado do projeto sem conhecer as intenções paródicas? Ou os cineastas apenas ressaltam a construção da performance como artifício, sobrepondo o caráter artificial da cultura (os gestos e a entonação particulares do gospel brasileiro) à natureza ao redor? O kitsch tende necessariamente ao ridículo, à falta de empatia? Ou o evidente refinamento da composição e montagem 
afasta a noção de desprezo? O filme proporcionou um importante debate sobre a ética das imagens. (CARMELO, 2017)

As indagações do crítico, mesmo desconhecendo os meandros da produção, levaram a uma leitura da obra que questionava a própria representação. Afinal, qual era o limite ético que permitia aos diretores representarem os cantores gospeis daquela forma? A estratégia estético-narrativa utilizada pelos realizadores também levou ao que o jornalista chamou de "debate sobre a ética das imagens". Segundo ele, ao utilizar uma estética kitsch, o filme estaria tendendo ao ridículo, à falta de empatia.

O filósofo Abraham Moles (1986), cuja obra é referência na teorização do movimento artístico conhecido como Kitsch, faz uma vasta retomada histórica da presença dessa manifestação na arte desde muito cedo, mas que vai se intensificar com a ascensão da classe burguesa, que passa a adquirir objetos artísticos e misturá-los com outros, sem valor de arte. Outro ponto, segundo Moles, na estética Kitsch, é que sua tipologia é composta sempre por materiais que se passam pelo que não são, ou que são dificilmente incorporados pelo que de fato são - a madeira é pintada como mármore, o plástico como fibra, e assim por diante. As coisas também estão deslocadas, em geral, de seu espaço natural, o que seria um princípio fundamental dessa estética: o da inadequação. O autor não diz nada, no entanto, sobre essa ligação entre o kitsch e a crueldade estética ou à falta de empatia, opinião produzida por Carmelo.

Ao refletir sobre essa estética em Terremoto santo, o crítico questiona se as pessoas - elas próprias - não estariam deslocadas de seu habitat, ou, mais profundamente, se ao serem demovidas em suas representações, não estariam suscetíveis a interpretações cruéis. Essa impressão é compartilhada por Bárbara Bergamaschi (2017): "A sensação é que vemos uma paródia da paródia, onde regime de visualidade das pentecostais foram desviados do seu uso original (como uma espécie de gentrificação) para endossar uma retórica dos diretores sobre a arte, em um diálogo exclusivo com seus pares". 
Em sua página do Facebook, a diretora Bárbara Wagner (2017) postou a crítica escrita por Bruno Carmelo e escreveu, antes do link da matéria: "Interessante confirmar que o filme parece falar mais de miradas de classe que de religião". Para ela, a repulsa dos críticos e dos presentes na sessão do Janela estava mais direcionada a um preconceito em relação às pessoas que eram retratadas ali do que à própria narrativa fílmica. Essa postagem foi fundamental para que pudéssemos mapear as diversas interpretações que se seguiram às críticas inclusive, o texto de Bárbara Bergamaschi também foi postado dias depois na sequência de discussão, nos comentários, e a jornalista tagueada, chamada a dar sua opinião no debate. No esquema seguinte (Figura 2) podemos observar a sequência temporal desses eventos de crítica.

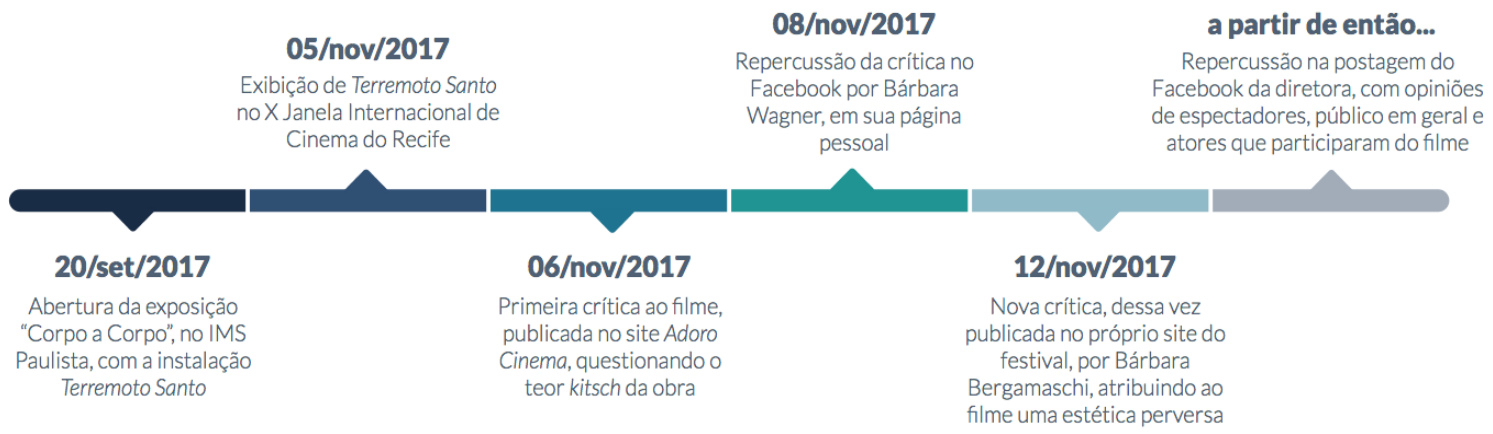

Figura 2: linha do tempo com síntese das circulações críticas de Terremoto santo

É interessante observar que, entre o público que dava suas próprias interpretações sobre o filme na página da realizadora, estavam pessoas que foram à sessão no festival; outras que viram o filme na mostra do Instituto Moreira Salles, em São Paulo; uma parcela que não viu a obra, mas que se interessou pela discussão e que versava sobre os limites da representação; e, entre eles, os próprios atores do filme.

Um deles, Joalyson Anderson (2017), escreveu ter gostado muito de participar do filme, "uma experiência incrível". Rebate a maneira como o público reagiu, o que para ele foi muito banal, pois "o filme foi feito no intuito de mostrar a fé cristã em forma de música, ou seja, do Louvor". Muitos outros, parte do público que assistiu 
ou não ao filme, destacaram essa mesma chave de interpretação, e projetaram no filme uma maneira de retratar as igrejas evangélicas, a partir de uma estética própria.

A partir das críticas - as já citadas, mas também outras que surgiram tempos depois, quando a exposição Corpo a corpo entrou em cartaz no Instituto Moreira Salles do Rio de Janeiro, como é o caso do texto de Hermano Callou (2018), na revista Cinética -, das entrevistas e dos depoimentos dos realizadores do curta em redes sociais, e nas inúmeras interpretações possíveis - e conflituosas - do filme nos espaços de discussão criados a partir da postagem de Bárbara Wagner, mapeamos as interpretações possíveis para a obra, buscando recriar o espaço público de sua circulação (Figura 3) a partir, como já mencionamos, de três esferas: a produção, a recepção dos críticos e as discussões nas redes.

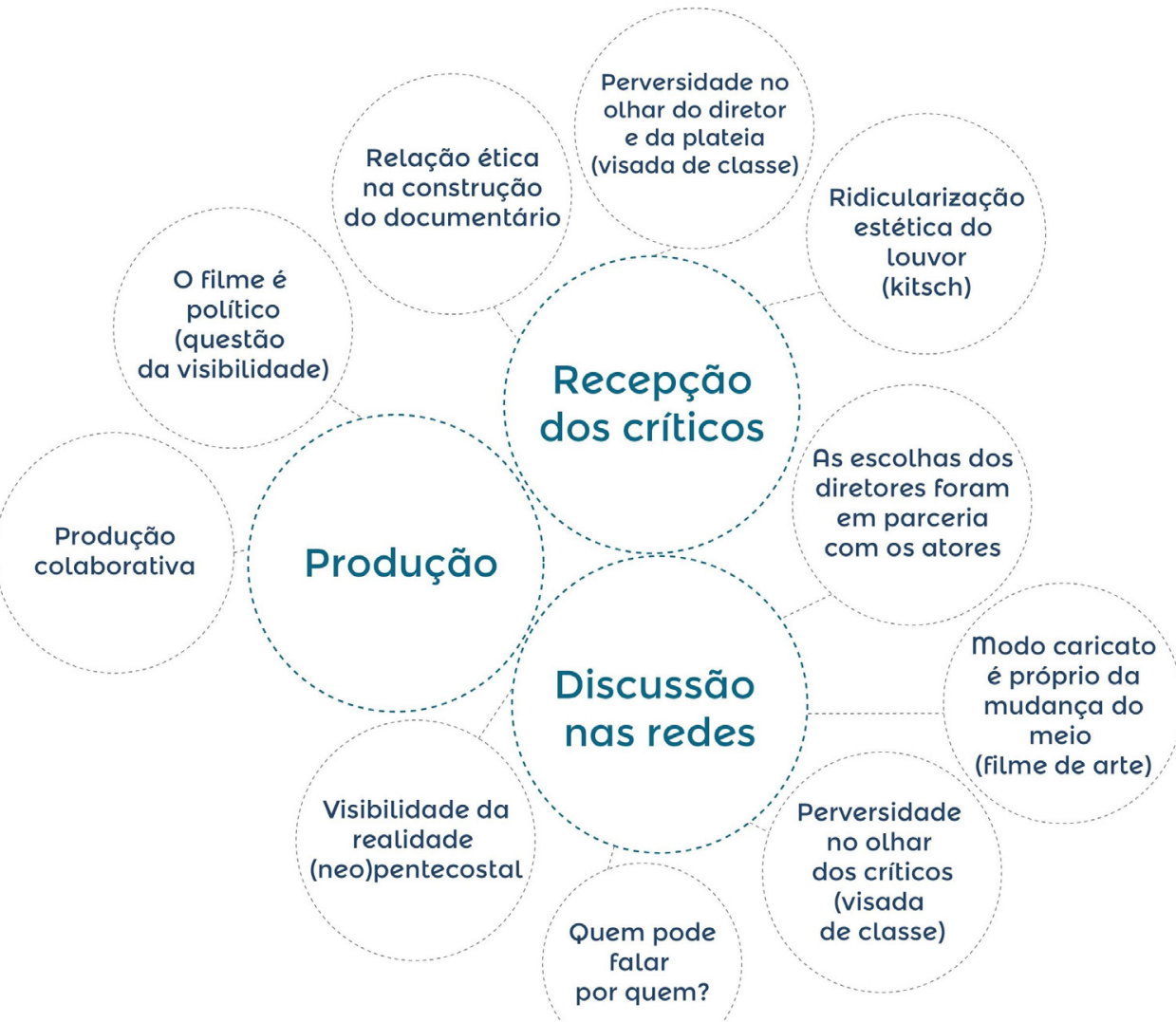

Figura 3: Mapeamento das interpretações em conflito nas recepções de Terremoto santo

A partir da Figura 3, podemos agrupar as narrativas em chaves interpretativas para refletir sobre as possíveis ancoragens da obra em seu complexo crítico. Uma 
delas é a questão ética e estética, ou as implicações éticas das escolhas estéticas dos realizadores. Essa abordagem está muito presente na recepção dos críticos, sendo bastante rebatida pela produção, e talvez seja o embate que mais gerou ruído na fruição da obra em sua circulação. Ainda que não sejam reivindicações que partiram de grupos sociais, foram incômodos presentes na crítica a partir de uma recepção ao filme que o tratou como um retrato humorístico, sarcástico, sobre a realidade gospel, grupo que, para os críticos, estava em posição de vulnerabilidade frente às decisões e as escolhas da produção.

Por outro lado, há questões identitárias que surgiram, em uma segunda principal chave de interpretação, sintetizada no questionamento de quem poderia falar por e no lugar de quem. Essa demanda pela voz dos próprios atores também foi recorrente na interação do público com os realizadores, mas não estava evidente na concepção dos críticos.

Do lado da produção, a interpretação que se sobressaiu foi a de legar aos espectadores e à crítica a responsabilidade por pensar que a obra era um retrato irônico ou cruel. A crueldade, então, estaria nos olhares sobre a representação, não na construção narrativa da obra em si. A dimensão política do filme estava presente a partir da visibilidade que daria a grupos evangélicos, cada vez mais numerosos e pouco representados nos circuitos de arte e de cinema, segundo os diretores. Ao discurso dos realizadores, também se aglutinam as interpretações da curadoria da mostra que exibiu por alguns meses Terremoto santo em São Paulo e no Rio de Janeiro: a questão que motivou a inclusão do filme em Corpo a corpo foi sua dimensão política, ou uma indagação mais ampla sobre até que ponto um corpo pode ser político.

\section{A ampliação das interpretações a partir do complexo crítico da obra}

No caso de Terremoto santo, em que as interpretações e a maneira como a obra circulou nas redes sociais permitiram uma ampliação das possíveis maneiras de ler o filme. Restringir a análise às críticas especializadas e à repercussão da obra após sua primeira exibição seria reproduzir uma quantidade próxima de interpretações, 
que se alternariam na defesa da escolha da produção por uma estética já utilizada pelos próprios cantores, e outra que condenaria esse deslocamento representativo para um outro ambiente de circulação.

No entanto, a inclusão das redes sociais nas análises sobre a obra, constituindo um complexo crítico expandido, nos permitiu uma pluralidade maior de interpretações, considerando não apenas os espectadores cujo ruído influenciou na concepção da obra, mas também os próprios atores e outras vozes implicadas na produção do filme. Para Soulez (2013b, p. 129), a recepção online das produções culturais representa uma ampliação do próprio espaço público, não porque uma nova articulação entre discussão política e debate sobre os filmes será inventada ou desenvolvida pelas práticas de rede, mas porque a dinâmica que a obra estabelece com suas interpretações, dessa maneira, agrega outros elementos de contestação, diálogo e embate, que não estariam presentes se considerássemos apenas a crítica especializada.

Portanto, as redes se comportariam, na perspectiva de sua composição em um complexo crítico, como conectoras de alteridades e confrontações, como uma costura de ligações à vezes confusas e aleatórias, mas que parecem priorizar uma expressão maior de gostos, interrogações e interpretações sobre os filmes. A ampliação, em rede, para interpretações mais diversas da obra torna o encontro de outros pontos de vista obrigatório e pode favorecer a deliberação das imagens e dos filmes, tanto junto aos espectadores quanto no próprio espaço público.

Ao buscar mapear as inúmeras possibilidades e chaves interpretativas de Terremoto santo, na tentativa de compreender quais as maneiras possíveis de ancoragem em um complexo crítico que influencia os espectadores no momento de sua deliberação, não pretendemos esgotar as maneiras de olhar para o filme, mas reconhecer a obra audiovisual como produto cultural, cuja interpretação e recepção estão indissociadas de seu contexto político, cultural, social e histórico. Portanto, remontar seu complexo crítico e o espaço público de circulação é, também, compor suas outras narrativas possíveis, a partir de uma perspectiva cada vez mais expandida de leitura. 


\section{Referências}

ANDERSON, J. Eu amei participar do filme. [S. I.], 15 nov. 2017. In: WAGNER, B. O kitsch tende necessariamente.... [S. I.], 8 nov. 2017. Facebook: Bárbara Wagner @barbara.wagner.142. Disponível em: https://bit.ly/2PaqI8g. Acesso em: 15 maio 2018.

AUMONT, J.; MARIE, M. Dicionário teórico e crítico de cinema. Campinas: Papirus, 2003.

BARTHES, R. Rhétorique de l'image. Communications, 4, p. 40-51, 1964.

BARTHES, R. O óbvio e o obtuso. Rio de Janeiro: Nova Fronteira, 1990.

BERGAMASCHI, B. Um dia da caça, outro do caçador. Janela de Cinema, Recife, 12 nov. 2017. Disponível em https: //bit.ly/2Zcv6bx. Acesso em: 15 maio 2018.

CALLOU, H. Espelhos do Poder. Cinética: cinema e crítica, [s. I.], 13 abr. 2018. Disponível em: https://bit.ly/2UCMFTD. Acesso em: 15 maio 2018.

CARMELO, B. Janela de Cinema 2017: competição brasileira de curtas começa em alto nível com animação sobre a ditadura e musical gospel. AdoroCinema, [s. I.], 6 nov. 2017. Disponível em: https://bit.ly/2XcEtGn. Acesso em: 15 maio 2018.

ESQUENAZI, J. P. Quand un produit culturel industriel est-il une "oeuvre politique"?. Réseaux, Paris, v. 3, n. 167, p. 189-208, 2011.

ISER, W. O ato da leitura. São Paulo: Editora 34, 1996. v. 1. 
JOLY, M. Introduction à l'analyse de l'image. Paris: Nathan, 1994.

METZ, C. Le perçu et le nommé. In: DUFRENNE, M. (org.). Vers une esthétique sans entrave. Paris: Union Générale D’Éditions, 1975.

METZ, C. Le signifiant imaginaire. Paris: Union Générale D'Éditions, 1977.

MOLES, A. O kitsch: a arte da felicidade. São Paulo: Perspectiva, 1986.

NOGUEIRA, T. Corpo a corpo: a disputa das imagens, da fotografia à transmissão ao vivo. Rio de Janeiro: Ed. IMS, 2017.

ODIN, R. Cinéma et production de sens. Paris: Armand Colin, 1997.

ODIN, R. De la fiction. Paris: De Boeck Université, 2000.

ODIN, R. Les espaces de communication: introduction à la sémio-pragmatique. Grenoble: Presses Universitaires de Grenoble, 2011.

SOARES, R. L.; SILVA, G. Lugares da crítica na cultura midiática. Comunicação, Mídia e Consumo, São Paulo, v. 13, n. 37, p. 9-28, 2016.

SOULEZ, G. Quand le film nous parle: rhétorique, cinéma et télévision. Paris: Presses Universitaires de France, 2011.

SOULEZ, G. La délibération des images. Vers une nouvelle pragmatique du cinéma et de l'audiovisuel. Communication \& langages, Paris, p. 3-32, 2013 a.

SOULEZ, G. Les agrégats délibératifs: et s'il n'y avait pas de 'communauté' d'interprétation?. Théorème, Paris, v. 17, p. 119-129, 2013b. 
TERREMOTO Santo. Direção: Bárbara Wagner e Benjamin de Burca. 2017. 1 vídeo (20 min), color. Cópia digital.

WAGNER, B. O kitsch tende necessariamente.... [S. I.], 8 nov 2017. Facebook: Bárbara Wagner @barbara.wagner.142. Disponível em: https://bit.ly/2PaqI8g. Acesso em: 15 maio 2018.

submetido em: 13 mar. 2019 | aprovado em: 20 abr. 2019 